\title{
Notícias de um precipício ou George Stocking Jr. e a antropologia vitoriana
}

\author{
Lilia Moritz Schwarcz e Íris Morais Araújo
}

George W. Stocking Jr. (1930-), professor emérito da Universidade de Chicago e conhecido investigador da história da antropologia - ainda pouco editado no Brasil $^{1}$-, iniciou sua série de estudos sobre o evolucionismo britânico com Victorian Anthropology, originalmente publicado em 1987 e cujo prólogo o leitor tem agora a oportunidade de ler, pela primeira vez, traduzido entre nós.

O objetivo do autor nesse livro, de maneira geral, é contextualizar a emergência da antropologia inglesa no momento de sua fundação como ciência moderna; assim como realizar uma avaliação da produção desse período, por ele denominado como "evolucionismo clássico". No entanto, e como bom antropólogo que é, Stocking nunca deixa de considerar o ponto de vista dos agentes em seu contexto e questóes próprias ao momento que as viu nascer.

Para compreender esses primeiros antropólogos ingleses, o autor investe em muitas frentes. De modo breve, é possível pensar o livro a partir de um conjunto de questôes que orquestram o material empírico e conduzem a investigação: a importância da ideia de civilização nas escolas de pensamento alemá, inglesa e francesa; as diferentes tradiçóes que se constituem nos momentos de nascimento da disciplina, e em tempos de domínio da rainha Vitória; os tipos de evidência empírica arregimentados pelos pensadores da época com o objetivo de discriminar quem eram os selvagens; os debates a respeito do progresso da civilizaçáo; o papel dos selvagens no debate darwiniano; e, finalmente, a maneira como esses embates levaram à conformação de uma ciência antropológica, naquele mesmo contexto.

Victorian Anthropology é certamente um livro cheio de meandros e que dificilmente se deixa aprisionar numa só leitura. O curto "Prólogo: um precipício no tempo" é sinal da vitalidade do empreendimento de Stocking Jr. Afinal, menos que reificar os desdobramentos de um certo pensamento evolucionista como simples resultado de um conjunto de forças externas - sejam elas políticas, culturais ou sociais -, o antropólogo norte-americano embaralha as cartas e propóe um jogo tenso entre a emergência da disciplina e suas condicionantes circunstanciais. E o mais interessante é a janela que Stocking Jr. escolhe abrir para observar a paisagem; seleciona um dos ícones da modernidade da qual a antropologia é tributária: as grandes exposiçôes universais, mais especificamente aquela que se desenvolveu no Palácio de Cristal, em 1851, em Londres. Ferro, vidro e vitrines; trilhos, locomotivas e passeios de fim de semana; certos interesses da Coroa Britânica coadunados com o novo fenômeno das multidóes que invadem o espaço público - e que sempre poderiam transmutar-se em classes perigosas dáo vida a esse espaço de celebração do progresso Oitocentista. Verdadeira vitrine dos projetos e aspiraçóes dessas elites encantadas pela miragem do progresso, as exposiçóes universais serviam, também, para didaticamente expor a evolução social; a barbárie ou a civilização. Portanto, nada mais adequado do que focar lentes e compreender desenhos hoje afastados temporalmente.

Mas, para o autor, esses elementos não bastam. O que interessa entender e desvendar é a lógica classificatória que permeia a organização presente no Palácio de Cristal. Por meio de quatro categorias - matérias-primas, maquinário, manufaturas e belas-artes - e códigos que misturam algarismos arábicos, romanos e letras do alfabeto latino, a produção material das diferentes "nações" - do Taiti à poderosa Grã-Bretanha - vai sendo apresentada ao público. O ordenamento é feito de várias naturalizaçôes e traz uma lógica precisa que divide o mundo à sua maneira 
290 | Lilia Moritz Schwarcz e Íris Morais Araújo

“e perfeição". Na verdade, tais disputas simbólicas entre os diferentes países que participam do evento representavam uma projeção dos grandes modelos imperiais. Basta notar, para tanto, a classificação dos artefatos alemães como "artesanato"; dos objetos presentes no estande francês como "de luxo"; ou o do país-sede como "indústria". Por outro lado, a dificuldade em relacionar as contribuiçôes das colônias - de esteiras pandanus a elefantes indianos - a esse modelo de Estado-nação, enfatiza o autor, revelam uma visão hierarquizada acerca das diferentes contribuições. Afinal, nesse caso, esses coletivos foram entendidos sob o rótulo fixo de "matéria-prima". Nos diferentes nomes e definições ficam evidentes divisóes e toda uma engenharia que alia tecnologia e avaliaçáo social, observando-se as culturas e suas produçôes a partir de uma régua que determina, discrimina e especifica superioridades e inferioridades, de maneira rígida e estanque. Não por acaso, o progresso era, então, entendido como único, evolutivo e obrigatório.

Nos termos de Stocking Jr., é nesse aspecto que se explicita a premissa que funda essa antropologia vitoriana: "nem todos os homens haviam avançado no mesmo passo, ou chegado ao mesmo ponto". Investigar os motivos desses desequilíbrios e desproporçóes transformava-se numa tarefa urgente e que deveria ser cumprida com rigor. É dessa época o investimento na montagem de coleçóes etnológicas e mesmo, segundo o autor, a criaçáo do método comparativo, tão caro à Antropologia contemporânea e que até hoje gera tanta polêmica e discussão.

Não há como deixar de pensar que o Palácio de Cristal vale por si uma boa etnografia.
Ainda mais porque aprendemos com Stocking Jr. que tal empreendimento permite jogar luz e entender de maneira mais abrangente a nascente antropologia, que começava a se delinear como uma disciplina particular. Muito se tem comentado sobre as origens espúrias, digamos assim, da antropologia, que teria surgido nos poróes dos navios imperiais e se associado ao pensamento darwinista social da época. No entanto, como o pensamento "é filho de seu tempo", nada como acompanhá-lo junto à sua época, com o objetivo de evitar avaliaçóes presentistas, anacronismos de toda sorte ou interpretaçôes muito condicionadas por uma agenda contemporânea. Stocking Jr. nos faz viajar, bem acompanhados, e revela, de maneira inesperada, como as origens de nossa disciplina sempre deram pano para muitas mangas.

\section{Notas}

1. Enquanto o autor publicou, em inglês (e para ficarmos apenas em alguns dos livros mais conhecidos), Race, Culture and Evolution (1968); Victorian Anthropology (1987); Colonial Situations: Essays on the Contextualization of Ethnographic Knowledge (org., 1991); The Ethnographer's Magic and Other Essays in the History of Anthropology (1992); After Tylor: British Social Anthropology, 1888-1951 (1995); Volksgeist as Method and Ethic: Essays on Boasian Ethnography and the German Anthropological Tradition (1996); Delimiting Anthropology: Occasional Inquiries and Reflections (2001), em português temos apenas a edição de $A$ formação da antropologia americana (2004), uma coletânea de textos de Franz Boas organizada pelo professor de Chicago.

autora Lilia Moritz Schwarcz

Professora Titular de Antropologia / USP

autora Íris Morais Araújo

Doutoranda em Antropologia Social / USP

Recebida em 17/11/2010

Aceita para publicação em 17/11/2010

cadernos de campo, São Paulo, n. 19, p. 289-290, 2010 